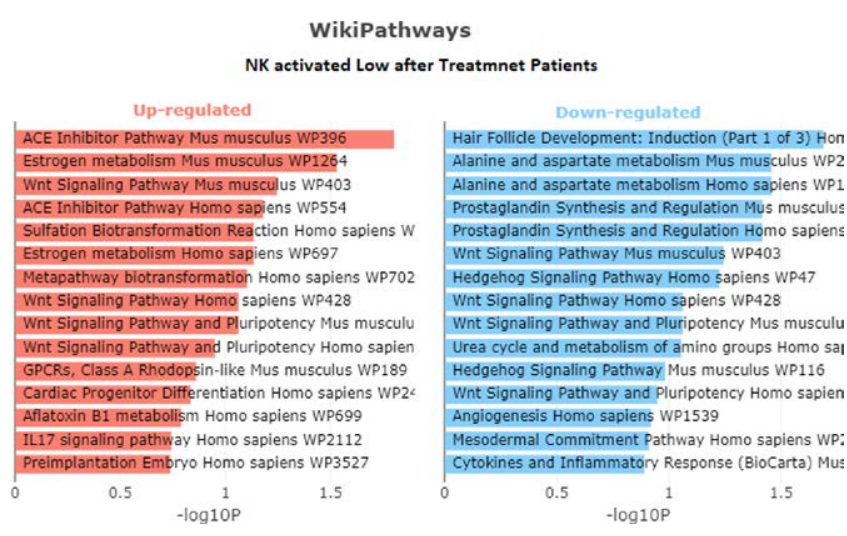

Figure 2. Top wikiPathways enriched in the patients with decreased percentage of synovial infiltrating activated NK after 6 months of tDMARD therapy compared to those who showed increased or unchanged percentage.

Conclusion: Synovial tissue NK cells, resting mast cells, plasma cells and M1 macrophages play major role in response to tDMARD. Genes related to WNT signaling, estrogen metabolism and IL17 signaling can help stratification of patients for a more effective personalized medicine in RA.

References:

[1] Smolen, J.S., D. Aletaha, and I.B. McInnes, Rheumatoid arthritis. Lancet (London, England), 2016. 388(10055): p. 2023-2038.

[2] Safari, F., et al., CRISPR and personalized Treg therapy: new insights into the treatment of rheumatoid arthritis. Immunopharmacology and immunotoxicology, 2018. 40(3): p. 201-211.

[3] Walsh, A.M., et al., Triple DMARD treatment in early rheumatoid arthritis modulates synovial $T$ cell activation and plasmablast/plasma cell differentiation pathways. PloS one, 2017. 12(9): p. e0183928-e0183928.

Disclosure of Interests: None declared

DOI: 10.1136/annrheumdis-2020-eular.6291

\section{AB0011 INFLUENCE OF IL17A GENE ON THE PATHOGENESIS OF IMMUNOGLOBULIN-A VASCULITIS}

F. Genre ${ }^{1}$, S. Remuzgo Martinez ${ }^{1}$, V. Pulito-Cueto ${ }^{1}$, D. Prieto-Peña ${ }^{1}$, B. AtienzaMateo $^{1}$, B. Sevilla ${ }^{2}$, J. Llorca ${ }^{3}$, N. Ortego ${ }^{4}$, L. Lera-Gómez ${ }^{1}$, M. Leonardo ${ }^{5}$, A. Peñalba ${ }^{5}$, M. J. Cabero ${ }^{5}$, L. Martín-Penagos ${ }^{6}$, J. A. Miranda-Filloy ${ }^{7}$, A. Navas Parejo $^{8}$, D. De Argila ${ }^{9}$, M. Aragües ${ }^{9}$, E. Rubio-Romero ${ }^{10}, M^{2}$. Leon Luque ${ }^{10}$, J. M. Blanco-Madrigal ${ }^{11}$, E. Galindez ${ }^{11}$, J. Martin Ibanez ${ }^{12}$, S. Castañeda ${ }^{13}$, R. Blanco ${ }^{1}$, M. A. González-Gay 1,14,15, R. López-Mejías ${ }^{1} .{ }^{1}$ Research Group on Genetic Epidemiology and Atherosclerosis in Systemic Diseases and in Metabolic Bone Diseases of the Musculoskeletal System, IDIVAL, Hospital Universitario Marqués de Valdecilla, Santander, Spain; ${ }^{2}$ Division of Pediatrics, Hospital Universitario San Cecilio, Granada, Spain; ${ }^{3}$ Epidemiology and Computational Biology Department, Universidad de Cantabria, and CIBERESP, IDIVAL,, Santander, Spain; ${ }^{4}$ Systemic Autoimmune Diseases Unit, Hospital Universitario San Cecilio, Granada, Spain; ${ }^{5}$ Division of Pediatrics, Hospital Universitario Marqués de Valdecilla, Santander, Spain; ${ }^{6}$ Nephrology Department, Hospital Universitario Marqués de Valdecilla, IDIVAL-REDINREN, Santander, Spain; ${ }^{7}$ Division of Rheumatology, Hospital Universitario Lucus Augusti, Lugo, Spain; ${ }^{8}$ Nephrology Department, Hospital Universitario San Cecilio, Granada, Spain; ${ }^{9}$ Dermatology Department, Hospital Universitario de La Princesa, Madrid, Spain; ${ }^{10}$ Rheumatology Department, Hospital Universitario Virgen del Rocío, Sevilla, Spain; ${ }^{11}$ Rheumatology Department, Hospital Universitario de Basurto, Bilbao, Spain; ${ }^{12}$ Instituto de Parasitología y Biomedicina 'López-Neyra', CSIC, PTS Granada, Granada, Spain;

${ }^{13}$ Rheumatology Department, Hospital Universitario de La Princesa, Madrid, Spain; 14 School of Medicine, University of Cantabria, Santander, Spain; 15 Cardiovascular Pathophysiology and Genomics Research Unit, School of Physiology, Faculty of Health Sciences, University of the Witwatersrand, Santander, Spain

Background: Cytokines signaling pathway genes represent a key component of the genetic network implicated in the pathogenesis of Immunoglobulin-A vasculitis (IgAV) [1], an inflammatory vascular pathology. Interleukin (IL)17A is a genetic risk locus for autoimmune diseases, such as giant cell arteritis [2] and spondyloarthritis [3].

Objectives: To determine the potential influence of IL17A on IgAV.

Methods: Five IL17A tag polymorphisms (rs4711998, rs8193036, rs3819024, rs2275913 and rs7747909) were genotyped in 360 Caucasian patients with IgAV and 1,003 sex and ethnically matched healthy controls.
Results: No statistically significant differences between patients with IgAV and healthy controls were observed when each IL17A genetic variant was analyzed independently. Similarly, no statistically significant differences between patients with IgAV and healthy controls were found when the five IL17A polymorphisms were evaluated combined conforming haplotypes. In addition, there were no statistically significant differences in genotype, allele and haplotype frequencies of IL17A when patients with IgAV were stratified according to the age at disease onset or to the presence/absence of gastrointestinal or renal manifestations. Conclusion: Our results do not support an influence of IL17A on the pathogenesis of IgAV.

References:

[1] Autoimmun Rev 2018; 17: 301-15

[2] Ann Rheum Dis 2014; 73: 1742-5

[3] Mediators Inflamm 2018; 2018: 1395823.

Acknowledgments: This study was supported by European Union FEDER funds and "Fondo de Investigaciones Sanitarias" (grant Pl18/00042) from "Instituto de Salud Carlos III' (ISCIII, Health Ministry, Spain). RL-M is a recipient of a Miguel Servet type I programme fellowship from the ISCIII, co-funded by the European Social Fund (ESF, 'Investing in your future') (grant CP16/00033) SR-M is supported by funds of the RETICS Program (RD16/0012/0009) (ISCIII, co-funded by the European Regional Development Fund (ERDF)). VP-C is supported by a pre-doctoral grant from IDIVAL (PREVAL 18/01). LL-G is supported by funds of PI18/00042 (ISCIII, co-funded by ERDF).

Disclosure of Interests: Fernanda Genre: None declared, Sara Remuzgo Martinez: None declared, Verónica Pulito-Cueto: None declared, D. Prieto-Peña: None declared, Belén Atienza-Mateo: None declared, Belén Sevilla: None declared, Javier Llorca: None declared, Norberto Ortego: None declared, Leticia Lera-Gómez: None declared, Maite Leonardo: None declared, Ana Peñalba: None declared, María Jesús Cabero: None declared, Luis Martín-Penagos: None declared, Jose Alberto Miranda-Filloy: None declared, Antonio Navas Parejo: None declared, Diego de Argila: None declared, Maximiliano Aragües: None declared, Esteban Rubio-Romero: None declared, MANUEL LEON LUQUE: None declared, Juan María Blanco-Madrigal: None declared, E. Galindez: None declared, Javier Martin Ibanez: None declared, Santos Castañeda: None declared, Ricardo Blanco Grant/research support from: Abbvie, MSD and Roche, Consultant of: Abbvie, Pfizer, Roche, Bristol-Myers, Janssen and MSD, Speakers bureau: Abbvie, Pfizer, Roche, Bristol-Myers, Janssen, Lilly and MSD, Miguel A González-Gay Grant/research support from: Pfizer, Abbvie, MSD, Speakers bureau: Pfizer, Abbvie, MSD, Raquel López-Mejías: None declared

DOI: 10.1136/annrheumdis-2020-eular.641

\section{AB0012 ROLE OF IRF5 GENE ON THE PATHOGENESIS OF IMMUNOGLOBULIN-A VASCULITIS}

S. Remuzgo Martinez ${ }^{1}$, F. Genre ${ }^{1}$, V. Pulito-Cueto ${ }^{1}$, D. Prieto-Peña ${ }^{1}$, B. AtienzaMateo $^{1}$, B. Sevilla ${ }^{2}$, J. Llorca ${ }^{3}$, N. Ortego ${ }^{4}$, L. Lera-Gómez ${ }^{1}$, M. Leonardo ${ }^{5}$, A. Peñalba ${ }^{5}$, M. J. Cabero ${ }^{5}$, L. Martín-Penagos ${ }^{6}$, J. A. Miranda-Filloy ${ }^{7}$, A. Navas Parejo $^{8}$, J. Sanchez Perez ${ }^{9}$, M. Aragües ${ }^{9}$, E. Rubio ${ }^{10}$, M. Leon Luque ${ }^{10}$, J. M. Blanco-Madrigal ${ }^{11}, E$. Galinde ${ }^{11}$, J. Martin Ibanez ${ }^{12}$, S. Castañeda ${ }^{13}$, R. Blanco ${ }^{1}$, M. A. González-Gay 1,14,15, R. López-Mejías ${ }^{1} .{ }^{1}$ Research Group on Genetic Epidemiology and Atherosclerosis in Systemic Diseases and in Metabolic Bone Diseases of the Musculoskeletal System, IDIVAL, Hospital Universitario Marqués de Valdecilla, Santander, Spain; ${ }^{2}$ Division of Pediatrics, Hospital Universitario San Cecilio, Granada, Granada, Spain; ${ }^{3}$ Epidemiology and Computational Biology Department, Universidad de Cantabria, and CIBERESP, IDIVAL, Santander, Spain; ${ }^{4}$ Systemic Autoimmune Diseases Unit, Hospital Universitario San Cecilio, Granada, Spain; ${ }^{5}$ Division of Pediatrics, Hospital Universitario Marqués de Valdecilla, Santander, Spain; ${ }^{6}$ Nephrology Department, Hospital Universitario Marqués de Valdecilla, IDIVAL-REDINREN, Santander, Spain; ${ }^{7}$ Division of Rheumatology, Hospital Universitario Lucus Augusti, Lugo, Spain; ${ }^{8}$ Nephrology Department, Hospital Universitario San Cecilio, Granada, Spain; ${ }^{9}$ Dermatology Department, Hospital Universitario de La Princesa, Madrid, Spain; ${ }^{10}$ Rheumatology Department, Hospital Universitario Virgen del Rocío, Sevilla, Spain; ${ }^{11}$ Rheumatology Department, Hospital Universitario de Basurto, Bilbao, Spain; ${ }^{12}$ Instituto de Parasitología y Biomedicina 'López-Neyra', CSIC, PTS Granada, Granada, Spain;

${ }^{13}$ Rheumatology Department, Hospital Universitario de La Princesa,, Madrid, Spain; 14 School of Medicine, University of Cantabria, Santander, Spain; 15 Cardiovascular Pathophysiology and Genomics Research Unit, School of Physiology, Faculty of Health Sciences, University of the Witwatersrand, Johannesburg, South Africa

Background: Interferon signaling pathway plays a relevant role in autoimmunity. Genetic variants in the interferon regulatory factor (IRF) 5 gene, that encodes the major regulator of the type I interferon induction [1], have been related to the development of several inflammatory diseases [2]. 